synaptic transmission have proved difficult to disentangle since usually more than one cell type meets the receptor at synaptic contact. At the synapse between receptor and depolarising bipolar cells, J-I. Toyoda (Kawasaki University) describing experiments to pass current trans-retinally produced evidence that at least two postsynaptic ionic channels are transmitter modulated. The hyperpolarising bipolar cells still conform to the original suggestion that light produces a permeability decrease to a single ion species.

A method to decouple the horizontal cells from their putative role in the feedback loop at the receptor triad synapse would be very helpful here, but failing this an interesting technique was reported by Yu. A. Trifonov and A. L. Byzov (Moscow University) to study the electrical properties of the horizontal cell membrane. Because of extensive electrical coupling between these cells, microelectrode studies of the cell membrane are not feasible; the method used here is a modification of Kramer's 'Winkel rinne', and results suggest cell membrane possesses anomaious rectification properties. Whether this will yield further information on the receptor synapse remains to be seen.

We may now be in a position to localise the cellular origins of the 'noise' treated in the psychophysical literature as the ultimate determinant of visual discrimination. Stressing this point, however, H. B. Barlow (University of Cambridge) tentatively suggested from experiments using random dot patterns that the factors which limit the quantum efficiency of seeing determined from performance tests may not arise in the retina at all but from "nasty central processes going on". Central limitations to quantum efficiency can only revise estimates of retinal efficiency upwards.

\section{Pesticides and the environment}

\author{
by Mary Lindley
}

A symposium on the ecological effects of pesticides, sponsored by the Institute of Biology and the Linnean Society was held in London on September 23-24. The proceedings will be published by Academic Press.

Pesticides are not likely to be abandoned to the accompaniment of cries of ecological doom, although they clearly can be misused and have caused death and destruction in some cases. DDT and its successors have wrought so much good in controlling disease and increasing crop productivity that they must continue to be used, albeit in moderation and with constant efforts to find alternatives. This was the message of the symposium, during which very few speakers discussed directly the ecological effects of pesticides.

According to H. C. Gough (Ministry of Agriculture, Fisheries and Food, London), the benefits of pesticides used correctly in agriculture far outweigh their hazards. Their use has greatly reduced losses of many crops from pests, diseases and weeds. Without pesticides, he said, production would decline and costs would increase. Unnecessary use occurs, however, and there is a continuing need to ensure that hazards are minimised in the application of pesticides.

A particularly hopeful development in crop protection from the ecological point of view is selectivity. I. J. Graham-Bryce (Rothamsted Experimental Station, Harpenden) cited in particular the pyrethroids, which are potent insecticides, through their actions as nerve poisons, but not harmful to mammals. Another target for selective pesticides is the endocrine system of insects; juvenile hormone analogues and anti-juvenile hormone compounds hold promise.

The control of pests and diseases in forests presents a greater dilemma than when agricultural crops are concerned. Pesticides are in any case more likely to upset biological equilibria in perennial than in annual plant environments and the multipurpose nature of many forests adds to the complications, as M. J. Way (Imperial College Field Station, Silwood Park, Ascot) explained. $\mathrm{He}$ pointed out that the balance between species in forests may indeed be maintained by pests: for example, without spruce budworm some forests would be monocultures of spruce. But on the whole, pesticides are used less in forestry than in other major production systems.

The disastrous ecological consequences of the use of herbicides to defoliate large tracts of forest in Vietnam during the recent war were described by Dr A. H. Westing (Stockholm International Peace Research Institute). Severe destruction of habitats was caused in more than 50,000 hectares of upland forest and in 150,000 hectares of mangrove forest during the American programme of spraying with 2,4-dichlorophenoxyacetic acid and 2,4.5-trichlorophenoxyacetic acid. According to Westing, the damage will be long lasting and has effectively deprived Vietnam of a proportion of its forests

The difficulties of monitoring the ecological effects of pesticides, particularly in developing countries, were made very clear by W. E. Kershaw and M. Pugh Thomas (University of Salford). They have been studying the effects of insecticides used to control the blackfly vector Simulium damnosum in the World Health Organization Onchocerciasis (river blindness) Control Programme. They have found that investigations of the biological side effects of pesticides on fast flowing rivers in Africa are expensive, tedious and hazardous. So far they have no evidence that fish have been affected, while the data obtained for invertebrates are very hard to interpret. Pugh Thomas believes that to allow for seasonal effects it will be necessary to compare data for successive years before a clear picture is likely to emerge.

The problems involved in predicting how pesticides will affect the environment were underlined by $F$. Moriarty (Institute of Terrestrial Ecology, Monks Wood Experimental Station, Huntingdon). Direct field trials are difficult, and the various indirect approaches used have disadvantages. But he said two tentative assumptions are possible: organisms have little effect on the amounts of pesticide in the physical environment, and if individual organisms are affected adversely, then ecological effects are imminent or already happening.

The prospects for wildlife, according to N. W. Moore (Nature Conservancy Council, London), depend more on the future of their habitats than on the use of pesticides. The decline in the wildlife population in Britain during the past 150 years has been due more to the destruction of habitats for land development than to the effects of pesticides. He pointed out, however, that treatment with pesticides can be locally damaging, and it will be increasingly important to ensure that pesticides do not spread away from the crops which they are protecting, for example by drift or in effluent. He said that the future of wildlife in the farmed countryside will depend on the conservation of areas of unfarmed habitat, where pesticides cannot reach.

Discussing future prospects for man, K. Mellanby (Institute of Terrestrial Ecology, Monks Wood Experimental Station) said that although in an ideal world pesticides would be unnecessary, they will continue to be used, and with proper precautions and controls, they can do their job while man's environment continues to be improved. He said that the dangers inherent in the use of pesticides are generally accepted and there has often been public overreaction to them. 